\title{
Non-pharmacological Interventions for Coping with COVID-19: A Rapid Systematic Review
}

\author{
Áquila Ramos-Milaré ${ }^{1}$, Daniele Lera-Nonose ${ }^{1}$, Mariana Terron-Monich $^{2}$, Thaís Santos ${ }^{2}$, \\ Izabel Demarchi ${ }^{3}$, Dennis Bertolini ${ }^{1}$, Maria Lonardoni ${ }^{1}$, and Jorge Teixeira ${ }^{1}$ \\ ${ }^{1}$ Universidade Estadual de Maringa \\ ${ }^{2}$ Universidade Estadual de Maringá \\ ${ }^{3}$ Universidade Federal de Santa Catarina
}

June 1, 2020

\begin{abstract}
Background: Non-pharmacological interventions (NPIs) remain central for the management of COVID-19 as there are no licensed vaccines or safe and effective antivirals to treat coronavirus yet. A rapid systematic review reported the main publications on NPIs to cope with the global COVID-19 outbreak. Methods: The research was conducted according to the PRISMA statement, from January 31 to March 31, 2020, in PubMed, Embase, Scopus, and Web of Science databases. Results: A total of 26 publications were included as comments, viewpoints, original articles, and studies on mathematical modeling. It was published by 251 researchers and four investigation groups from 23 countries. Conclusion: In summary, the publications pointed out that the social isolation, staying home, social distancing, quarantine, and contact tracing are essential and that NPIs could be combined to cope with the COVID-19 outbreak. It is recommended to value, intensify, and commend the efforts of countries that have implemented NPIs as extremely bold and robust measures to contain coronavirus disease.
\end{abstract}

\section{Non-pharmacological Interventions for Coping with COVID-19: A Rapid Systematic Review}

\section{Running title: Non-pharmacological Interventions}

${ }^{1}$ Áquila Carolina Fernandes Herculano Ramos-Milaré ${ }^{1}$ Daniele Stéfanie Sara Lopes Lera-Nonose; ${ }^{1}$ Mariana de Souza Terron-Monich; ${ }^{2}$ Thaís da Silva Santos; ${ }^{2,3}$ Izabel Galhardo Demarchi; ${ }^{1}$ Dennis Armando Bertolini; ${ }^{1}$ Maria Valdrinez Campana Lonardoni, ${ }^{2 *}$ Jorge Juarez Vieira Teixeira

${ }^{1}$ Postgraduate in Health Sciences. Health Sciences Program. State University of Maringá, Maringá, PR. Maringá, Paraná, Brazil.

${ }^{2}$ Postgraduate Program in Biosciences and Physiopathology. Department of Clinical Analysis and Biomedicine. State University of Maringá, Maringá, Paraná, Brazil.

${ }^{3}$ Department of Clinical Analysis. Federal University of Santa Catarina, Florianópolis, SC. Brazil.

*Correspondent authors 
Department of Clinical Analysis and Biomedicine, State University of Maringá - UEM, Colombo Avenue, 5790, Code 87020-900, Maringá, Paraná, Brazil. Phone: 00554430114878 , Electronic address: jjvteixeira@gmail.com.

\section{Hosted file}

Main text.docx available at https://authorea.com/users/327996/articles/455396-nonpharmacological-interventions-for-coping-with-covid-19-a-rapid-systematic-review

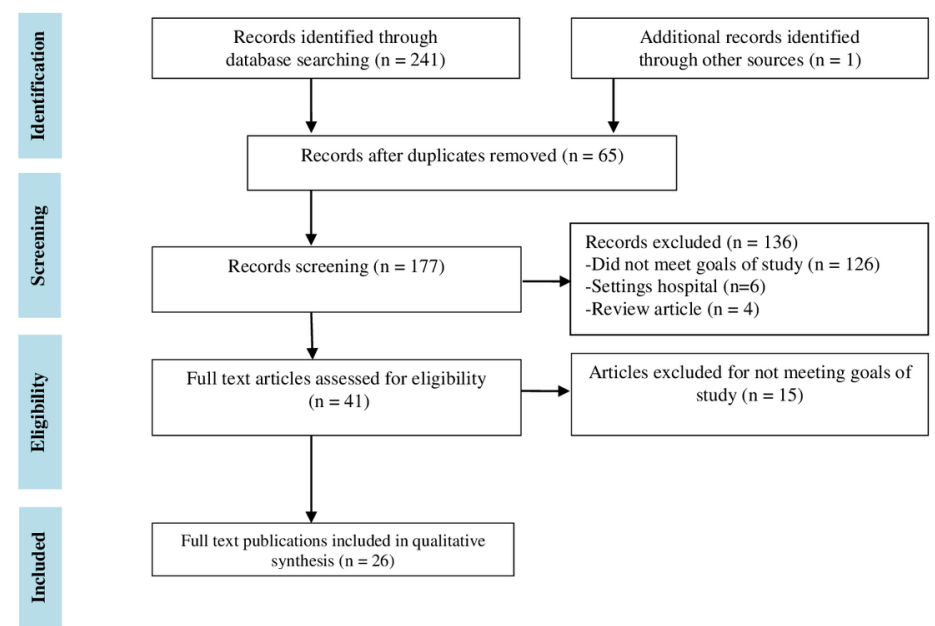

